\title{
Perbedaan Efektivitas Pemberian Minyak Zaitun (Olive oil) dengan Virgin Coconut Oil (VCO) terhadap Penyembuhan Ruam Popok pada Bayi Usia 6-12 Bulan di Wilayah Kerja Puskesmas Pandanwangi Malang
}

\author{
Ainun Nikmah ${ }^{1 *}$ ), Yuseva Sariati ${ }^{2}$, Nur Aini Retno Hastuti ${ }^{3}$ \\ $\left.{ }^{1 *}\right)$ Program Studi Sarjana Kebidanan Fakultas Kedokteran Universitas Brawijaya, Malang, \\ Jawa Timur, Indonesia, Email: anikmah4@gmail.com, Hp.: +6282257112006 \\ 2 Program Studi Profesi Bidan Fakultas Kedokteran Universitas Brawijaya, Malang, Jawa Timur, \\ Indonesia, Email: sariati.yuseva@gmail.com, Hp.: +6281320512316 \\ ${ }^{3}$ Program Studi Sarjana Kebidanan Fakultas Kedokteran Universitas Brawijaya, Malang, Jawa \\ Timur, Indonesia, Email: nurainiretno@ub.ac.id, Hp.: +6285642140459
}

\begin{abstract}
Diaper rash is inflammation that occurs in the area around the folds of the thighs, buttocks and genetalia. Diaper rash can be divided into 3 degrees, mild, moderate and severe. Diaper rash can be handled with non-pharmacological treatment by giving olive oil and virgin coconut oil (VCO). Olive oil is a vegetable oil containing oleic acid containing reserves and tocopherol $\alpha$ which works as an antioxidant that counteracts free radicals while $\mathrm{VCO}$ is a vegetable oil containing lauric acid and tocopherol $\alpha$ which contains the same function as olive oil. Olive oil has the highest content of oleic acid and tocopherol $\alpha$, namely extra virgin olive oil (EVOO). This research aimed to prove If there is a difference between the provision of EVOO with VCO to prevent mild or moderate diaper rash in infants aged 6-12 months. This study used a Quasi Experiment research design type pre-test and post-test design. Samples were selected based on inclusion criteria with the number of samples $(n=$ 32). 16 babies receive EVOO and 16 babies therapy at VCO. Bivariate analysis using the Wilcoxon test. The results of the study showed the influence of giving EVOO showed a p-value of 0.011 and a negative rating of 4.00 while the contribution of giving VCO showed a p-value of 0,000 and a negative rating of 8.50 . The negative rating difference of 4.50 can be considered in comparison with the help of EVOO with VCO for the recovery of mild or moderate degrees of diaper rash in infants aged 6-12 months.
\end{abstract}

Keywords: diaper rash, extra virgin olive oil (EVOO), virgin coconut oil (VCO)

\begin{abstract}
ABSTRAK
Ruam popok merupakan peradangan yang terjadi di area sekitar lipatan paha, pantat serta genetalia. Ruam popok dibedakan menjadi 3 derajat yakni derajat ringan, sedang dan berat. Ruam popok dapat ditangani dengan pengobatan non farmakologis yakni pemberian minyak zaitun dan virgin coconut oil (VCO). Minyak zaitun merupakan minyak nabati yang mengandung asam oleat yang berfungsi menurunkan peradangan dan tokoferol a berfungsi sebagai antioksidan yang menangkal radikal bebas sedangkan VCO merupakan minyak nabati yang mengandung asam laurat dan tokoferol a yang mempunyai fungsi yang sama dengan minyak zaitun. Minyak zaitun yang mempunyai kandungan asam oleat dan tokoferol a paling tinggi yakni jenis extra virgin olive oil (EVOO). Penelitian ini bertujuan untuk membuktikan adanya perbedaan efektivitas dalam pemberian minyak zaitun jenis EVOO dengan VCO terhadap penyembuhan ruam popok derajat ringan-sedang pada bayi usia 6-12 bulan. Penelitian ini menggunakan desain penelitian Quasi Experiment dengan pre-test dan post-test design. Sampel berjumlah 32 bayi usia 6-12 bulan. 16 bayi mendapatkan terapi EVOO dan 16 bayi mendapatkan terapi VCO pada kasus ruam popok Analisis bivariat menggunakan uji Wilcoxon. Hasil penelitian pengaruh pemberian EVOO menunjukkan $p$-value 0,011 dan negative ranks 4,00 sedangkan
\end{abstract}


pengaruh pemberian VCO menunjukkan $p$-value 0,000 dan negative ranks 8,50 . Disimpulkan bahwa VCO lebih efektif dalam proses penyembuhan ruam popok derajat ringan-sedang pada bayi usia 6-12 bulan.

Kata kunci: ruam popok, extra virgin olive oil (EVOO), virgin coconut oil (VCO)

*Korespondensi: Ainun Nikmah. Surel: anikmah4@gmail.com

\section{PENDAHULUAN}

Ruam popok merupakan peradangan yang terjadi di sekitar area genetalia, pantat dan lipatan paha yang disebabkan oleh kontak yang terusmenerus dengan pemakaian popok. Pemakaian popok, terutama popok sekali pakai mempunyai kelebihan dapat menampung BAB dan BAK bayi yang terjadi secara tiba-tiba sehingga popok sekali pakai mejadi kebutuhan primer bagi orang tua dalam pemenuhan kebutuhan bayi. Ruam popok disebabkan oleh beberapa hal yakni gesekan antara kulit sekitar area genetalia, pantat dan lipatan paha dengan feses dan urin yang tertampung lama, kelembaban yang tidak terjaga, alergi terhadap bahanbahan yang terkandung dalam popok dan infeksi bakteri atau jamur ${ }^{1}$. Di Indonesia, sebanyak 7-35\% bayi mengalami ruam popok dan angka tertinggi kejadian ruam popok pada bayi terjadi pada usia 6-12 bulan² .

Berdasarkan manifestasi klinisnya, derajat keparahan ruam popok diklasifikasikan menjadi 3 yakni derajad ringan, sedang dan berat. Derajat ringan ditandai dengan adanya kemerahan di sekitar area genetalia, pantat dan lipatan paha. Derajat sedang yang ditandai dengan adanya kemerahan, benjolan atau bintik-bintik kecil serta lesi ringan di sekitar area genetalia, pantat dan lipatan paha. Derajat berat yang ditandai dengan adanya kemerahan yang semakin meluas di sekitar area genetalia, pantat dan lipatan paha hingga ke punggung disertai benjolan atau bintik-bintik kecil yang berisi pus karena infeksi jamur (Candida albicans) atau bakteri (Staphylococcus aureus) $)^{3}$. Pencegahan dan penanganan ruam popok yang paling utama adalah menjaga kebersihan dan kelembaban area yang tertutup oleh popok yakni area genetalia, pantat dan lipatan paha. Pola pembersihan yang baik dan benar yakni dengan menggosok kulit bayi yang tertutup oleh popok dengan lembut juga dapat mencegah terjadinya ruam popok pada bayi. Pada bayi dengan ruam popok dapat dilakukan 2 jenis penanganan yakni dengan penanganan farmakologis atau non farmakologis. Penanganan farmakologis pada ruam popok menggunakan salep/krim yang mengandung zinc oxide, pada ruam popok derajat berat diberikan krim yang mengandung antibiotik dan anti jamur seperti nistatin, clotrimazole, miconazole dan hydrocortisone (obat kortikosteroid untuk meredakan inflamasi) ${ }^{4}$. Penanganan farmakologis ruam popok dapat diberikan topikal alternatif seperti pemberian minyak zaitun (olive oil) dan virgin coconut oil. Kedua minyak tersebut mempunyai kandungan vitamin $\mathrm{E}$ yang berupa tokoferol a yang tinggi (sekitar 90\%).

Minyak zaitun merupakan minyak yang dihasilkan dari buah zaitun segar. Hal yang membedakan minyak zaitun dengan minyak nabati lainnya yakni minyak zaitun mempunyai kandungan asam oleat atau omega 9 (55-83\%). Minyak zaitun terdiri dari 5 jenis yakni extra virgin olive oil (EVOO), virgin olive oil (VOO), refined olive oil, pure olive oil dan extra light olive oil. ${ }^{5}$. 
Penanganan topikal alternatif yang lain yakni pemberian VCO (Virgin Coconut Oil). Virgin coconut oil merupakan minyak yang dihasilkan dari daging buah kelapa segar bewarna bening dan mempunyai daya simpan sampai 12 bulan $^{6}$. Virgin coconut oil mempunyai kandungan asam laurat dengan kadar $48 \%$ yang membedakan dengan minyak nabati yang lain. Jika dimasukkan ke dalam tubuh, asam laurat akan diubah dalam bentuk monogliserida yakni mono laurin yang berfungsi sebagai anti inflamasi dengan meningkatkan produksi interleukin 2 sama seperti kandungan asam oleat pada minyak zaitun. Virgin coconut oil juga mengandung tokoferol a dengan kadar sekitar $90 \%$ yang berfungsi sebagai antioksidan alami dan menangkal radikal bebas dalam tubuh ${ }^{7}$. Selain asam laurat dan tokoferol $\alpha$, kandungan lain virgin coconut oil yakni gliserol dan squalene.

Penelitian ini menggunakan minyak zaitun jenis extra virgin olive oil (EVOO) karena EVOO merupakan minyak dari perasan pertama buah zaitun yang mempunyai kandungan asam oleat dan tokoferol a yang tidak banyak terbuang akibat proses produksi. Tujuan dari penelitian ini adalah menganalisis perbedaan efektivitas pemberian minyak zaitun jenis EVOO dengan VCO terhadap penyembuhan ruam popok derajat ringan atau sedang pada bayi usia 6-12 bulan. EVOO dengan VCO yang diberikan diharapkan mempunyai perbedaan efektivitas yang signifikan untuk mengetahui penanganan yang lebih efektif.

\section{METODE PENELITIAN}

\section{Rancangan/Desain Penelitian}

Desain dalam penelitian ini menggunakan Quasi Experiment dengan pre-test and post-test design.
Analisis data menggunakan uji Wilcoxon.

\section{Ethical Clearance}

Penelitian ini telah mendapatkan keterangan kelaikan etik dengan No. 15/EC/KEPK.S1-KB/01/2020.

\section{Sasaran Penelitian}

Populasi penelitian adalah semua bayi usia 6-12 bulan yang memakai popok sekali pakai atau diaper di Wilayah Kerja Puskesmas Pandanwangi Kota Malang. Sampel sebanyak 32 responden dengan 2 kelompok perlakuan. Kelompok pemberian extra virgin olive oil (EVOO) sebanyak 16 responden dan kelompok perlakuan pemberian virgin coconut oil sebanyak 16 responden. Sampel penelitian yang dipilih berdasarkan kriteria inklusi yakni bayi usia 6-12 bulan dengan pertumbuhan dan perkembangan yang baik sesuai usia, memakai popok sekali pakai >12 jam, mengalami ruam popok derajat ringan atau sedang, tidak sedang mendapatkan pengobatan, dan keluarga dari bayi usia 6-12 bulan bersedia menjadi responden.

Extra virgin olive oil yang diberikan kepada subyek penelitian di produksi oleh Borges agricultural \& industri edible oils, Spanyol, diimpor oleh PT. Prambanan Kencana Jakarta dengan no. BPOM RI ML 109709012134. Sedangkan virgin coconut oil yang diberikan kepada subyek penelitian diproduksi oleh CV Aji Saka Kelapa dengan no. BPOM RI MD 207913001821. EVOO dan virgin coconut oil diberikan sebanyak 3 tetes yang dilakukan setiap pagi dan sore 
hari setelah mandi selama 5 hari berturut-turut.

\section{Teknik Analisis Data}

Analisis data pada penelitian ini menggunakan software SPSS 25. Tahapan pertama adalah pengolahan dan pengkodean data. Tahapan kedua adalah melakukan uji normalitas Shapiro-Wilk dan uji homogenitas Levene Test data. Jika $p$ value $>0,05$ maka data disebut berdistribusi normal dan homogen. Tahapan ketiga adalah untuk mengetahui perbedaan efektivitas antara minyak zaitun dengan VCO menggunakan uji Wilcoxon.

\section{HASIL PENELITIAN}

Tabel 1. Distribusi responden dalam pemberian minyak zaitun jenis extra virgin olive oil (EVOO) dan virgin coconut oil (VCO)

\begin{tabular}{|c|c|c|}
\hline Responden & $\mathrm{N}$ & $\begin{array}{c}\text { Persentase } \\
(\%)\end{array}$ \\
\hline Diberikan EVOO & 16 & 50 \\
\hline Diberikan VCO & 16 & 50 \\
\hline Total & 32 & 100 \\
\hline
\end{tabular}

distribusi frekuensi bayi yang diberikan EVOO dan VCO masing-masing sebanyak 16 bayi sehingga total responden sebanyak 32 bayi dengan klasifikasi ruam popok derajat ringan dan sedang.

Tabel 2. Frekuensi derajat ruam popok bayi sebelum dan sesudah diberikan minyak zaitun jenis extra virgin olive oil (EVOO)

\begin{tabular}{lcccc}
\cline { 2 - 5 } $\begin{array}{c}\text { Derajat } \\
\text { ruam } \\
\text { popok }\end{array}$ & \multicolumn{2}{c}{ Sebelum } & \multicolumn{2}{c}{ Sesudah } \\
\cline { 2 - 5 } & $\mathbf{n}$ & $\mathbf{( \% )}$ & $\mathbf{N}$ & $\mathbf{( \% )}$ \\
\hline Tanpa & 0 & 0 & 7 & 43,8 \\
ruam & & & & \\
Ringan & 14 & 87,5 & 8 & 50 \\
Sedang & 2 & 12,5 & 1 & 6,2 \\
Total & 16 & 100 & 16 & 100 \\
\hline
\end{tabular}

Berdasarkan tabel diatas, sebelum diberikan extra virgin olive oil sebanyak 14 bayi (87,5\%) termasuk dalam kategori ruam derajat ringan dan ruam popok derajat sedang sebanyak 2 bayi (12,5\%). Sedangkan, responden yang mengalami ruam popok setelah diberikan extra virgin olive oil (EVOO) sebanyak 9 bayi. 7 bayi $(43,8 \%)$ mengalami penuruan derajat ruam sehingga ruam menghilang, 8 bayi $(50 \%)$ dan 1 bayi $(6,2 \%)$ masingmasing mengalami ruam derajat ringan dan sedang.

Tabel 3. Frekuensi derajat ruam popok bayi sebelum dan sesudah diberikan minyak zaitun jenis virgin coconut oil (VCO)

\begin{tabular}{|c|c|c|c|c|}
\hline \multirow{2}{*}{$\begin{array}{c}\text { Derajat } \\
\text { ruam } \\
\text { popok }\end{array}$} & \multicolumn{2}{|c|}{ Sebelum } & \multicolumn{2}{|c|}{ Sesudah } \\
\hline & $\mathbf{N}$ & $(\%)$ & $\mathbf{N}$ & $(\%)$ \\
\hline $\begin{array}{l}\text { Tanpa } \\
\text { ruam }\end{array}$ & 0 & 0 & 15 & 93,8 \\
\hline Ringan & 13 & 81,2 & 1 & 6,2 \\
\hline Sedang & 3 & 18,8 & 0 & 0 \\
\hline Total & 16 & 100 & 16 & 100 \\
\hline
\end{tabular}

bayi sedang mengalami ruam popok derajat ringan dan sedang. Sebanyak 13 bayi $(81,2 \%)$ termasuk kategori ruam derajat ringan dan 3 bayi $(18,8 \%)$ termasuk kategori ruam derajat sedang sebelum mendapatkan terapi VCO. Sedangkan, responden yang mengalami ruam popok setelah diberikan virgin coconut oil sebanyak 1 bayi $(6,2 \%)$. Ruam popok yang terjadi yakni ruam popok derajat ringan. Sebanyak 15 bayi $(93,8 \%)$ mengalami penurunan derajat ruam sehingga ruam menghilang setelah 5 hari pemberian VCO.

Tabel 4. Pengaruh pemberian minyak zaitun jenis extra virgin olive oil (EVOO) terhadap penyembuhan ruam popok derajat ringan atau sedang pada bayi usia 6-12 bulan 


\begin{tabular}{ccccc} 
& & N & Mean & Sig. \\
\hline $\begin{array}{cccc}\text { Sebelum } \\
\text { dan }\end{array}$ & $\begin{array}{c}\text { Negativ } \\
\text { e ranks }\end{array}$ & 7 & 4,00 & \\
\cline { 2 - 3 } $\begin{array}{c}\text { sesudah } \\
\text { diberikan } \\
\text { EVOO }\end{array}$ & $\begin{array}{c}\text { Positive } \\
\text { Ranks }\end{array}$ & 0 & & 0,011 \\
\cline { 2 - 3 } & Ties & 9 & &
\end{tabular}

Berdasarkan tabel 4 disimpulkan bahwa penurunan derajat ruam dari pre test ke post test (negative ranks) sebanyak 7 orang dengan rata-rata 4,00. Hasil uji statistik Wilcoxon menunjukkan nilai signifikan (2-tailed) 0,011 . Data tersebut menyimpulkan adanya pengaruh pemberian minyak zaitun jenis EVOO terhadap penyembuhan ruam popok derajat ringan atau sedang.

Tabel 5. Pengaruh pemberian virgin coconut oil (VCO) terhadap penyembuhan ruam popok pada bayi usia 6-12 bulan

\begin{tabular}{|c|c|c|c|c|}
\hline & & $\mathbf{N}$ & Mean & Sig. \\
\hline \multirow{3}{*}{$\begin{array}{l}\text { Sebelum } \\
\text { dan } \\
\text { sesudah } \\
\text { diberikan } \\
\text { VCO }\end{array}$} & $\begin{array}{l}\text { Negativ } \\
\text { e ranks }\end{array}$ & 16 & 8,50 & \multirow{3}{*}{0,000} \\
\hline & $\begin{array}{c}\text { Positive } \\
\text { Ranks }\end{array}$ & 0 & & \\
\hline & Ties & 9 & & \\
\hline
\end{tabular}

Berdasarkan tabel 5 disimpulkan bahwa penurunan derajat ruam dari pre test ke post test (negative ranks) sebanyak 16 orang dengan rata-rata 8,50. Hasil uji statistik Wilcoxon menunjukkan nilai signifikan (2-tailed) 0,000 . Demikian pula, disimpulkan bahwa VCO terbukti berpengaruh terhadap proses penyembuhan ruam derajat ringan atau sedang.

Berdasarkan rata-rata dari kedua data tersebut, rata-rata penurunan derajat ruam pre test ke post test pemberian EVOO yakni sebesar 4,00 sedangkan rata-rata penurunan derajat ruam pre test ke post test pemberian virgin coconut oil (VCO) yakni sebesar 8,50. Perbedaan rata-rata penurunan sebesar 4,50 menyatakan bahwa VCO lebih efektif daripada EVOO dalam proses penyembuhan ruam.

\section{PEMBAHASAN}

Berdasarkan hasil penelitian, dari total 32 responden, sebanyak 27 responden mengalami ruam popok derajat ringan dan 5 responden mengalami ruam popok derajat sedang. Ruam popok pada bayi adalah peradangan di daerah kulit bayi yang tertutup popok, sering terjadi di daerah lipatan paha, genetalia dan pantat. Ruam popok disebabkan oleh beberapa hal yakni gesekan antara kulit sekitar area genetalia, pantat dan lipatan paha dengan feses dan urin yang tertampung lama, kelembaban yang tidak terjaga, alergi terhadap bahan-bahan yang terkandung dalam popok dan infeksi sekunder oleh bakteri (Staphylococcus aureus) atau jamur (Candida albicans) ${ }^{1}$.

\section{Pengaruh Pemberian Extra Virgin Olive Oil (EVOO) terhadap Penyembuhan Ruam Popok pada Bayi Usia 6-12 Bulan di Wilayah Kerja puskesmas Pandanwangi}

Berdasarkan uji analisis Wilcoxon, disiimpulkan bahwa terdapat penurunan derajat ruam dari pre test ke post test dengan nilai rata-rata negative ranks 4,00 dengan nilai signifikan 0,011 ( $p$ value $<0,05)$. Hal ini selaras dengan penelitian yang berjudul "Pengaruh Pemberian Minyak Zaitun (Olive oil) terhadap Ruam Popok (Diaper rash) di Desa Tebaloan Gresik" diketahui bahwa minyak zaitun yang diberikan dapat menurunkan derajat ruam popok dengan memperhatikan takaran yang tepat serta penggunaan yang baik dan benar sesuai lokasi adanya ruam $^{8}$. Penelitian ini juga sesuai dengan penelitian yang berjudul "Pemberian Extra Virgin Olive Oil untuk Mengatasi 
Diaper Rash (Ruam Popok) pada Bayi Usia 1-12 Bulan" menyimpulkan bahwa EVOO dapat menyembuhkan ruam popok $^{9}$.

Minyak zaitun yang diberikan dalam penelitian ini adalah minyak zaitun jenis extra virgin olive oil. Extra virgin olive oil adalah minyak zaitun perasan pertama dengan perasan dingin yang diperoleh dari buah zaitun yang masih segar. Extra virgin olive oil melewati tahapan produksi yang singkat sehingga kandungan antioksidan tidak banyak yang terbuang (sekitar 1-5\%) ${ }^{5}$. Minyak zaitun jenis extra virgin olive oil diberikan $2 x$ sehari selama 5 hari ${ }^{8}$.

Kandungan vitamin $\mathrm{E}$ dalam extra virgin olive oil (EVOO) yang terbanyak adalah jenis $\alpha$ tokoferol. $\alpha$ tokoferol mempunyai fungsi untuk menurunkan inflamasi dan memperbaiki sel-sel kulit yang mati. Inflamasi menurun karena a tokoferol dapat merangsang peningkatan produksi interleukin 2 yang berperan sebagai kekebalan tubuh terhadap inflamasi ${ }^{10}$. Selain vitamin E, EVOO juga mengandung vitamin B2 yang berfungsi mempercepat penyembuhan luka, vitamin $\mathrm{C}$ yang berfungsi meningkatkan sistem imun dalam menangkal radikal bebas dan vitamin $\mathrm{K}$ yang berfungsi dalam mengurangi inflamasi dengan cepat ${ }^{11}$. Minyak zaitun mengandung unsaturated acid yakni asam oleat sebanyak $83 \%{ }^{12}$. Asam oleat berperan penting dalam menurunkan inflamasi pada saat ruam. Asam oleat juga berperan dalam merusak membran lipid bakteri sehingga sistem kekebalan tubuh meningkat.

\section{Pengaruh Pemberian Virgin Coconut Oil (VCO) terhadap Penyembuhan Ruam Popok pada Bayi Usia 6-12 bulan di Wilayah Kerja Puskesmas Pandanwangi}

Berdasarkan uji analisis perbedaan data pre test dan post test menggunakan uji Wilcoxon, didapatkan hasil nilai signifikan 0,000 ( $p$ value $<0,05)$ sehingga disimpulkan bahwa terdapat pengaruh pemberian virgin coconut oil terhadap penyembuhan ruam popok derajat ringan atau sedang pada bayi usia 6-12 bulan di Wilayah Kerja Puskesmas Pandanwangi. Hal ini sesuai dengan penelitian yang berjudul "Pengaruh Virgin Coconut Oil Terhadap Ruam Popok Pada Bayi" yang menggunakan uji Wilcoxon juga disimpulkan bahwa virgin coconut oil mampu mengatasi ruam popok ${ }^{6}$. Jika dipakai secara topikal, virgin coconut oil akan menghasilkan asam lemak bebas yang berfungsi dalam menjaga kelembaban kulit ${ }^{13}$.

Penelitian ini juga sesuai dengan penelitian yang berjudul "Pengaruh Pemberian Virgin Coconut Oil (VCO) terhadap Ruam Popok pada Bayi" bahwa terdapat perbedaan ruam antara bayi sebelum dan sesudah diberikan $\mathrm{VCO}^{14}$. Virgin coconut oil merupakan minyak yang dihasilkan dari daging buah kelapa segar. Virgin coconut oil mempunyai warna yang bening dan daya simpan yang lebih dari 12 bulan.

Virgin coconut oil mengandung asam lemak jenuh rantai sedang yakni asal laurat sebanyak $48 \%$. Kandungan asam laurat inilah yang membedakan virgin coconut oil dengan minyak nabati lainnya. Selain sebagai anti inflamasi, asam laurat juga berperan dalam proses ketengikan akibat oksidasi sehingga daya simpan bertambah cukup lama yakni lebih dari 12 bulan ${ }^{7}$. Asam laurat yang masuk ke dalam tubuh akan diubah menajdi monogliserida yakni monolaurin yang berfungsi dalam merusak membran lipid bakteri. Berdasarkan teori, selain asam lemak virgin coconut oil juga mengandung vitamin E. Vitamin E 
dalam VCO dan EVOO mempunyai fungsi yang sama sebagai antioksidan yang menetralkan radikal bebas serta menurunkan inflamasi ${ }^{15}$.

3. Perbedaan Efektivitas Pemberian Minyak Zaitun Jenis Extra Virgin Olive Oil (EVOO) dengan Virgin Coconut Oil (VCO) terhadap Penyembuhan Ruam Popok pada Bayi Usia 6-12 bulan di Wilayah Kerja Puskesmas Pandanwangi

Berdasarkan tabel 6 dan 7 diketahui bahwa pemberian EVOO dan VCO mampu menurunkan derajat ruam popok pada bayi. Namun, terdapat perbedaan penurunan sebagian besar derajat ruam popok antara pemberian EVOO dengan VCO. Kelompok perlakuan yang diberikan VCO sebanyak 16 responden yang terdiri dari 13 responden mengalami ruam popok derajat ringan dan 3 responden mengalami ruam popok derajat sedang. Setelah diberikan VCO, 15 responden tidak mengalami ruam ruam (dengan persentase 93,8\%) dan 1 responden mengalami ruam popok derajat ringan.

Berdasarkan hasil uji analisis Wilcoxon, pemberian EVOO dan VCO mempunyai pengaruh terhadap penurunan derajat ruam popok. Berdasarkan rata-rata dari hasil kedua data tersebut, penurunan (negative rank) derajat ruam pre test ke post test masing-masing pemberian extra virgin olive oil (EVOO) sebesar 4,00 sedangkan pemberian virgin coconut oil (VCO) sebesar 8,50. Selisih ratarata penurunan sebesar 4,50 menyatakan bahwa pemberian VCO lebih efektif dibandingakan dengan pemberian EVOO dalam proses penyembuhan ruam. Penelitian ini juga selaras dengan penelitian yang berjudul "Efektifitas Minyak Kelapa dan Minyak Zaitun terhadap Pencegahan Diaper Dermatitis pada Anak Usia 3-24 Bulan di RSUD Tugurejo Semarang" yang menyatakan bahwa pemberian minyak kelapa lebih efektif dibandingkan pemberian minyak zaitun ${ }^{16}$.

Extra virgin olive oil (EVOO) dan virgin coconut oil (VCO) mempunyai manfaat yang sama yakni melembabkan kulit dan menurunkan inflamasi. Berdasarkan teori, EVOO dan VCO masing-masing mengandung asam oleat dan asam laurat ${ }^{6}$. Kedua asam lemak tersebut berfungsi untuk merusak membran lipid bakteri dan menurunkan inflamasi sehingga kekebalan tubuh meningkat. Selain itu, EVOO dan VCO mempunyai kandungan vitamin $E$ berupa $\alpha$ tokoferol yang mempunyai peranan penting dalam menetralkan radikal bebas dalam tubuh dan meningkatkan produksi interleukin 2 yang meningkatkan sistem kekebalan tubuh dalam mengurangi inflamasi ${ }^{11,15}$. Berdasarkan penelitian sebelumnya, EVOO dan VCO diberikan selama 5 hari berturut-turut setiap sesudah mandi di pagi hari dan sore hari6,8.

\section{SIMPULAN}

Berdasarkan hasil penelitian, terdapat perbedaan efektivitas pemberian minyak zaitun jenis EVOO dengan virgin coconut oil (VCO) terhadap penyembuhan ruam popok pada bayi usia 6-12 bulan di Wilayah Kerja Puskesmas Pandanwangi Kota Malang. VCO lebih efektif dalam proses penyembuhan ruam popok derajat ringan-sedang pada bayi usia 6-12 bulan. 


\section{DAFTAR PUSTAKA}

1. Dwienda, OR, Maita, L, Saputri, EM, \& Yulviana,

$\mathrm{R}$. 2014. Buku Ajar Asuhan. Kebidanan Neonatus, Bayi/ Balita dan Anak Prasekolah. Yogyakarta: Deepublish.

2. Andi, M. 2012. Diaper rash. Jakarta: artikel kesehatan. http://diaperrashpadabayi.html diakses pada tanggal 24 Juni 2019.

3. Ullya, et al.,. 2018. Hubungan Antara Pengetahuan dan Perilaku lbu dalam Pemakaian Disposble Diapers pada Batita dengan Kejadian Ruam Popok. Jurnal Kedokteran Diponegoro Vol. 7, Nomor 2, Mei 2018.

4. Blume-Peytavi, U. \& Kanti, V. Prevention and Treatmen of Diaper Dermatitis. Pediatric Dermatology., 35, pp. s19-s23 (2018).

5. Astawan, Made, dkk.,. 2015. Fakta dan Manfaat Minyak Zaitun. Jakarta: Buku Kompas.

6. Cahyati, Dwi, Antarini Idriansari, and Arie Kusumaningrum. "Pengaruh Virgin Coconut Oil Terhadap Ruam Popok Pada Bayi." Jurnal Keperawatan Sriwijaya 2.1 (2015): 5763.

7. Syah, Andi Nur A. 2005. Virgin Coconut Oil. Jakarta: Agro Media.

8. Pontoh, Arimina Hartati. Pengaruh Pemberian Minyak Zaitun(Olive oil) terhadap Ruam Popok(Diaper rash)di Desa Tebaloan Gresik. Akademi Kebidanan Griya Husada (2013).

9. Puspitasari, Pristi D., dkk.,. 2016. Pemberian Extra Virgin
Olive Oil (EVOO) untuk Mengatasi Diaper Rash (Ruam Popok) pada Bayi Usia 1-12 Bulan. Jurnal Kesehatan hesti Wira Sakti Vol. 4 No. 2.

10. Keast, R. et al.,. Molecular Mechanisms of Inflammations, Antiinflammatry Benefits of Virgin Olive Oil and the Phenolic Compound Oleocathal. Current Pharmaceutical Desigh Vol. 7 Issue: 8 (2011).

11. Cahyanto, Heri Nur. Perawatan Perianal dengan Minyak Zaitun Terhadap Derajat Ruam Popok Pada Bayi. Jurnal Penelitian Ksehatan Suara Forikes Vol. 9 No. 1. (2018).

12. Setyaningsih, Yana Agus dan Iradatul Hasanah. 2017. Pengaruh Minyak Zaitun (Olive oil) terhadap Penyembuhan Ruam Popok pada Bayi Usia 0-12 Bulan di Desa Sukobanah Kabupaten Sampang Madura.

13. Alamsyah, A.N. 2006. Virgin Coconut Oil Minyak Penakluk Aneka Penyakit. Jakarta: Agromedia Pustaka

14. Firmansyah, dkk.,Pengaruh Pemberian Virgin Coconut Oil (VCO) terhadap Ruam Popok pada Bayi. Celebes Heakth Journal. Vol. 1 No. 1 April (2019).

15. Apriyanti, Maya. 2012. 10 Tanaman Obat Paling Berkhasiat \& Paling Dicari. Purwomartini Kalasan Sleman Yogyakarta: Pustaka Baru Press

16. Watti, Weny W. dkk.,. Efektifitas Minyak Kelapa dan Minyak Zaitun terhadap Pencegahan Diaper Dermatitis pada Anak Usia 3-24 Bulan di RSUD Tugurejo Semarang. Karya IImiah STIKES Telogorejo Vol. 3 (2015) 